\title{
Rancang Bangun Farming Box Dengan Pengaturan Suhu Menggunakan Fuzzy Logic Controller
}

\author{
Riza Agung Firmansyah ${ }^{1 *)}$, and Dani Junianto ${ }^{2)}$ \\ 1,2) Jurusan Teknik Elektro-FTETI, Institut Teknologi Adhi Tama Surabaya, Indonesia \\ Corresponding Email: ${ }^{*}$ rizaagungf@itats.ac.id
}

\begin{abstract}
Implementation of control systems has been carried out in many fields of science. One of it applications is in the agriculture fields. In this research we implemented a control system on farming in a box. Farming in a box is a system that uses old shipping containers for the purpose of growing plants in any environment. Inside shipping containers is fully assembled hydroponic pipe with air temperature control. In this research was built a little farming box from acryclic to imitate a shipping container. Main focus of this research is design an air temperature control using fuzzy logic controller. Fuzzy logic controller was choosen because many existing farming box use on off controller. In some application, fuzzy logic controller has better performance than on off controller. Farming box temperature is controlled by blowing cool air using an electric fan. In this case, cool air is produced by cold side of peltier. Electric fan speed is controlled by pulse width modulation signal (PWM) that generated from microcontroller. Air temperature data feedback is obtained from DHT 11 sensor that installed in a acrylic box. Sensor is physically connected with microcontroller and Fuzzy logic controller is embedded in microcontroller as an algorithm. Fuzzy logic controller was design with error temperature and error difference as an input, and duty cycle of PWM signal as output. Fuzzy logic controller system performs to reduce the temperature from $31,6^{\circ} \mathrm{C}$ to set poin $28^{\circ} \mathrm{C}$ in 71 seconds. Steady state error obtained by $1.28 \%$ and better than uncontrolled system that obtain steady state error $7,14 \%$.
\end{abstract}

Key words: Farming in a box, Fuzzy Logic Controller, Temperature Control

\section{Pendahuluan}

Peranan sektor pertanian cukup penting dalam kehidupan bermasyarakat. Saat ini laju pertumbuhan penduduk dan peningkatan infrastruktur di Indonesia tidak sebanding dengan luas lahan pertanian yang sudah ada, dimana lahan pertanian tergantikan dengan bangunan-bangunan serta infrastruktur yang ada. Jika jumlah penduduk bertambah dan lahan pertanian semakin berkurang maka akan muncul kerawanan pangan. Namun kerawanan pangan dapat diatasi dengan membangun sistem pertanian di kota jika dirancang dengan tepat dan berkelanjutan [1].

Salah satu langkah yang bisa dilakukan untuk membangun sistem pertanian di kota adalah dengan menerapkan urban farming. Urban farming yaitu pemanfaatan lahan minimalis atau pemanfaatan pada gedung-gedung yang tak terpakai, lantai bawah tanah dan gudang yang tidak terpakai agar bisa dimaksimalkan fungsinya sebagai lahan pertanian [2].

Tidak seperti bertani pada umumnya di lahan terbuka, inovasi ini juga dapat meminimalisir gagal panen yang dikarenakan anomali cuaca dan perubahan iklim yang tak menentu. Ini didapat karena pengontrolan parameter seperti suhu dan kelembaban di monitor serta dikontrol oleh sensor dan teknologi modern. Pada urban farming sendiri ada beberapa pilihan dalam pengaplikasiannya yaitu hidroponik, aquaponik dan aeroponik [3].

Namun tidak semua tanaman bisa ditanam di sembarang tempat. Selain faktor lahan, ada faktor lain yang mendukung tumbuhya sebuah tanaman, salah satunya adalah faktor suhu udara. Sebagai contoh tanaman selada akan optimal bila ditanam pada suhu $15^{\circ} \mathrm{C}$ hingga $25^{\circ} \mathrm{C}$ [4]. Berbeda dengan tanaman tomat yang membutuhkan suhu $24^{\circ} \mathrm{C}$ hingga $28^{\circ} \mathrm{C}$ agar dapat tumbuh dengan baik [5]. Tanaman kangkung darat memiliki suhu tanam optimal pada suhu $25^{\circ} \mathrm{C}$ hingga $30^{\circ} \mathrm{C}$ [6]. Berdasarkan permasalahan tersebut maka tidak semua tanaman bisa ditanam di kota karena suhu cenderung panas. Sehingga diperlukan sebuah pengaturan suhu.

Salah satu teknik pertanian yang dapat menggabungkan urban farming dengan pengaturan lingkungan adalah farming in a box. Farming in a box merupakan teknik menanam hidroponik yang dilakukan di dalam box kontainer bekas sehingga dapat dikendalikan kondisi lingkunganya [7]. Contoh ruangan di dalam box tersebut ditunjukkan oleh Gambar 1. Dikarenakan ukuran box yang terbatas, maka akan mempermudah dalam mengatur suhu bahkan kelembaban udaranya. Dengan cara ini maka memungkinkan kita untuk menanam tanaman suhu rendah di perkotaan yang memiliki suhu yang tinggi. Piranti box kontainer dalam penelitian ini lebih lanjut akan disebut sebagai farming box.

Untuk melakukan pengaturan suhu maka diperlukan beberapa peralatan seperti kipas, perangkat pendingin atau pemanas dan lainya. Pengaturan suhu pada sebuah greenhouse dilakukan oleh Pambayun \& Sumarna [8] dengan menggunakan sensor LM35DZ sebagai sensornya. Proses pendinginan dilakukan dengan membuang udara panas di dalam ruangan menggunakan exhaust fan. Sistem kontrol yang diterapkan adalah ON/OFF dengan cara menyalakan atau mematikan kipas menggunakan relay. Sistem tersebut dirancang agar suhu ruangan stabil di bawah $34^{\circ} \mathrm{C}$. Pengaturan suhu dilakukan dengan menyalakan kipas saat suhu diatas $34^{\circ} \mathrm{C}$ dan memetikan kipas jika suhu dibawah $34^{\circ} \mathrm{C}$. Namun jika siang hari, suhu terendahnya sama dengan suhu ruang. 
Hasil yang di dapatkan sistem kontrol tersebut steady state error hingga lebih dari dari $20 \%$. Kelemahan ini bisa diatasi dengan menambahkan udara dingin dari luar yang didapatkan dari sistem pendingin khusus menyerupai air conditioner (AC). Perbaikan terhadap sistem kontrol ON/OFF juga bisa dilakukan dengan menggantinya dengan kontroler lain, misal fuzzy logic controller.

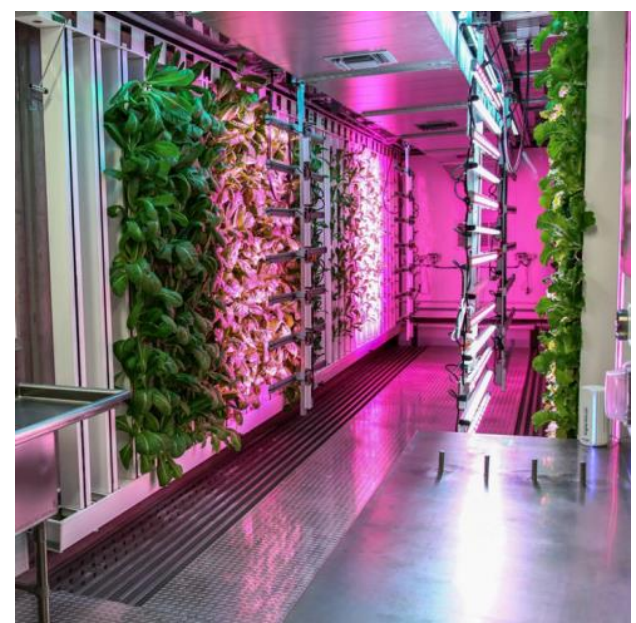

Gambar 1. Contoh farming box [7]

Sistem pendingin pada hidroponik juga dikembangkan Nahdi et al [9] menggunakan peltier. Peltier merupakan komponen yang menghasilkan dingin disalah satu sisi dan panas disisi lainnya, peltier akan mengasilkan panas dan dingin saat diberikan tegangan. Namun sistem kontrol yang diterapkan masih menggunakan sistem kontrol ON/OFF. Jika suhu berada di atas set poin mana peltier diaktifkan, sedangkan saat suhu dibawah set poin maka peltier di matikan. Dalam penelitian tersebut set poin yang digunakan adalah $25^{\circ} \mathrm{C}$.

Dari beberapa masalah yang telah diuraikan, maka dalam penelitian ini dibuat sebuah rancang bangun farming box yang dilengkapi dengan sistem pengaturan suhu otomatis. Pengaturan suhu dilakukan dengan memberikan udara dingin/panas menggunakan kipas yang terkopel dengan peltier. Putaran kipas diatur menggunakan sistem kontrol logika fuzzi (Fuzzy Logic Controller) yang algoritmanya ditanamkan di sebuah mikrokontroler. Data yang didapatkan dari penelitian ini adalah performa Fuzzy Logic Controller (settling time dan steady state error) dalam mengatur suhu farming box. Batasan dan ruang lingkup penelitian ini tidak diujikan secara langsung menggunakan tanaman sehingga untuk referensi set poin akan digunakan suhu $28^{\circ} \mathrm{C}$. Sedangkan kelembaban yang merupakan variabel penting untuk sementara diabaikan karena dalam penelitian ini difokuskan ke temperaturnya terlebih dahulu.

\section{Metodologi}

Berdasarkan latar belakang yang telah disampaikan, maka penelitian ini berfokus untuk membuat rancang bangun farming box yang dilengkapi dengan pengaturan suhu. Proses pembuatan rancang bangun farming box hingga sistem kontrolnya akan di jelaskan pada bagian ini.

\section{A. Perancangan Farming box}

Rancang bangun farming box yang dibuat, memiliki bentuk box balok dengan dimensi $61,2 \mathrm{~cm}$ x $51,2 \mathrm{~cm} \times$ $50,5 \mathrm{~cm}$. Bahan yang digunakan adalah acrylic dengan alasan mudah untuk dibentuk, cukup kuat, dan tidak mudah pecah. Didalam box tersebut terdapat sebuah bak untuk ditanami sayuran. Dalam penelitian ini tanaman yang digunakan adalah kangkung darat. Untuk memberikan suhu yang lebih dingin, digunakan kipas yang terhubung dengan sisi dingin peltier. Untuk memberikan suhu yang lebih panas, digunakan udara dari luar box yang cenderung lebih panas. Kipas yang digunakan ada tiga yang susunanya dapat dilihat pada Gambar 2.

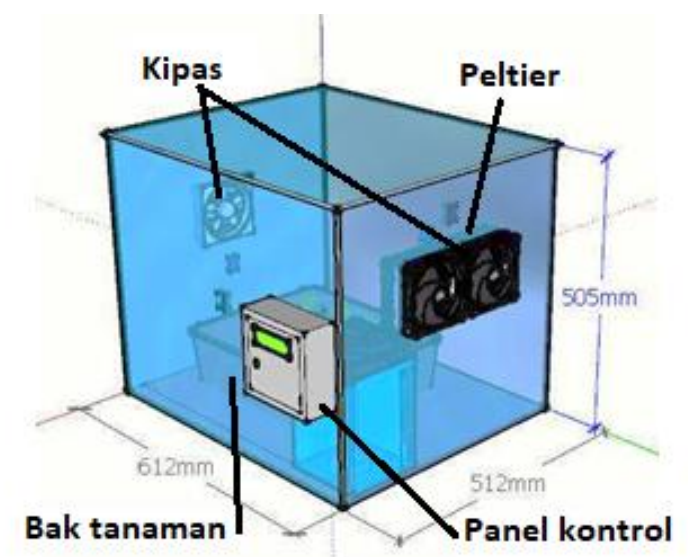

Gambar 2. Desain Rancang Bangun Farming box

Untuk mendapatkan udara dingin yang maksimal, peltier direkatkan ke satu buah heatsink di tiap sisi. Sisi panas diberi kipas untuk membuang panas ke arah luar sedangkan sisi dingin diberi kipas untuk memberikan udara dingin ke dalam box. Konfigurasi peltier, heatsink, dan kipas dapat dilihat pada Gambar 3. Dari perancangan tersebut maka didapatkan sebuah farming box yang dapat dilihat pada Gambar 4.

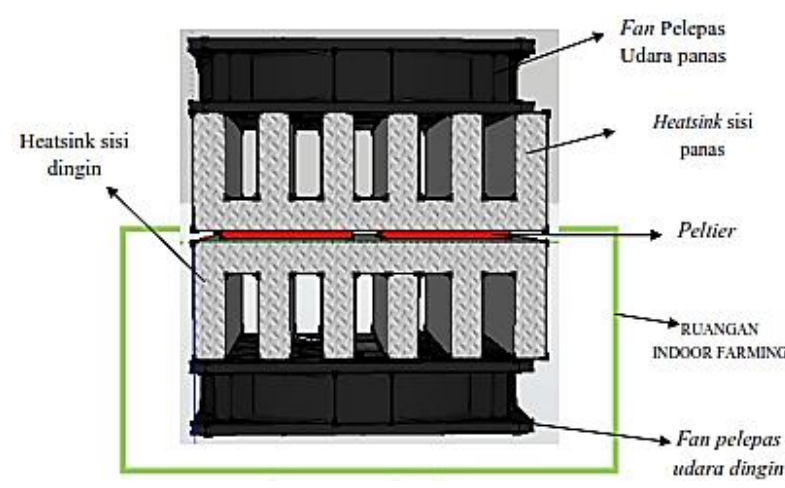

Gambar 3. Konfigurasi peltier, heatsink, dan kipas 


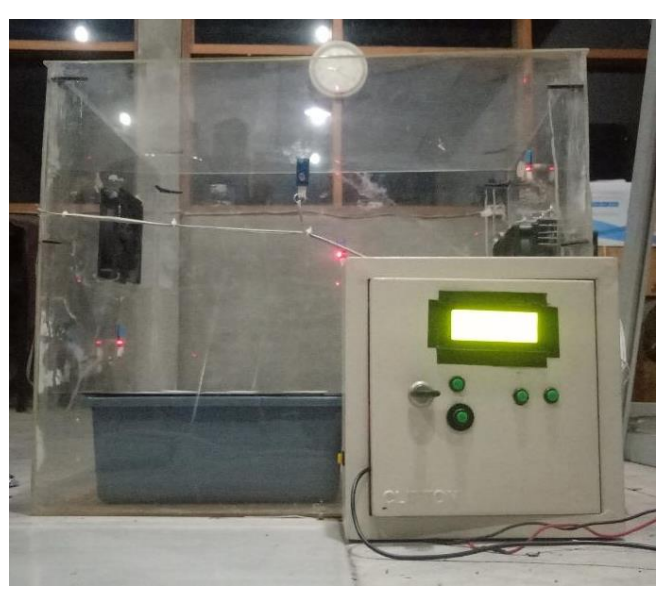

Gambar 4. Hasil realisasi farming box

\section{B. Perancangan perangkat keras (hardware)}

Untuk mengendalikan suhu agar stabil, maka diperlukan sebuah perangkat elektronik. Seperti yang telah dijelaskan sebelumnya bahwa pengaturan suhu dilakukan dengan sirkulasi udara sehingga aktuator yang digunakan adalah kipas. Peltier hanya digunakan untuk menghasilkan udara dingin sehingga tidak dilakukan pengendalian, hanya dinyalakan saja. Diagram blok perangkat keras yang digunakan, dapat dilihat pada Gambar 5.

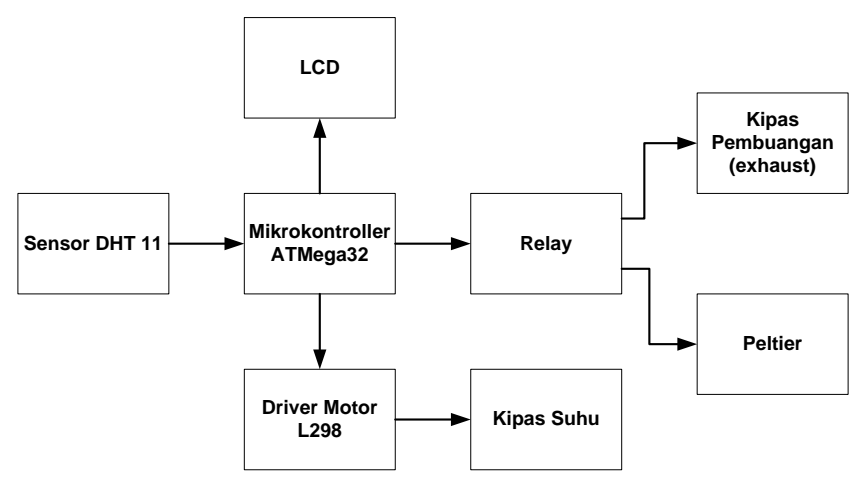

Gambar 5. Diagram blok hardware

Agar mikrokontroler dapat mengendalikan kecepatan kipas maka digunakan driver motor DC L298. LCD digunakan sebagai user interface yang menunjukan suhu aktual, dan beberapa variabel yang perlu diamati. Pembacaan suhu dilakukan dengan sensor DHT11. Sensor DHT11 tersebut sudah dikemas dalam sebuah modul sehingga sudah memiliki pengkondisi sinyal di dalamnya. Pembacaan data dilakukan dengan komunikasi serial one wire communication. Jika kabel yang digunakan dibawah 20m maka dapat langsung digunakan tanpa rangkaian pengkondisi sinyal tambahan [10]. Untuk mendapatkan distribusi suhu yang merata, digunakan sensor DHT11 sebanyak empat buah. Ke empat sensor tersebut diletakan pada setiap sisi box. Peletakan sensor dapat dilihat pada Gambar 6. Hasil pembacaan ke empat sensor lalu diambil nilai rata-ratanya untuk mendapatkan nilai suhu terukur.

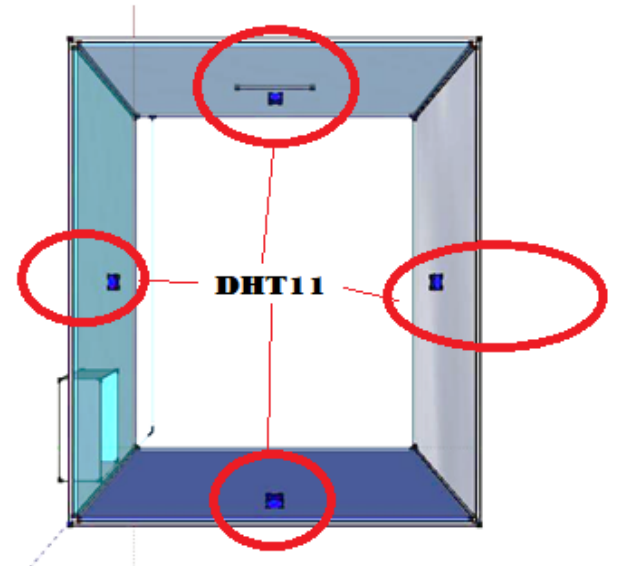

Gambar 6. Posisi peletakan sensor DHT11

\section{Perancangan Sistem Kontrol Fuzzy Logic Controller}

Variabel utama yang dikendalikan adalah suhu ruangan di dalam farming box. Suhu tersebut dibaca menggunakan sensor DHT 11 yang selanjutnya diumpanbalikan ke sistem kontrol. Mikrokontroler sebagai piranti kontrol utama membaca data dari sensor lalu menghitung nilai error berdasarkan nilai set poin yang diberikan. Set poin yang digunakan dalam penelitian ini sebesar $28^{\circ} \mathrm{C}$. Nilai tersebut dipilih karena merupakan nilai tengah dari suhu tanam kangkung darat yang berkisar antara $25^{\circ} \mathrm{C}-30^{\circ} \mathrm{C}$. Selain nilai error, selisih error juga dicari dengan membandingkan error sekarang dengan error pada proses sampling sebelumnya. Nilai error (e) maupun selisih error (de) selanjutnya diproses menggunakan logika fuzzy untuk mencari nilai duty cycle sinyal pwm yang digunakan untuk mengatur putaran kipas. Perubahan kecepatan kipas akan berpengaruh terhadap suhu di dalam farming box. Desain sistem kontrol ini dibuat sesuai dengan diagram blok Gambar 7.

Logika fuzzy yang digunan terdiri dari dua input dan satu output. Input pertama adalah error yang didapatkan dengan membandingkan pengukuran suhu dengan set poin. Input error memiliki tiga buah himpunan keanggotaan yaitu error negative (EN), error zero (EZ), dan error positive (EP). Sedangkan untuk input kedua yaitu selisih error, himpunan keanggotaanya juga terdiri menjadi tiga. Himpunan keanggotaan tersebut antara lain selisih negatif/delta error negative (DEN), selisih error nol/ delta error zero (DEZ), dan selisih positif/delta error positive (DEP). Fungsi keanggotaan dari kedua input ini dapat dilihat pada Gambar 8 dan Gambar 9 berikut.

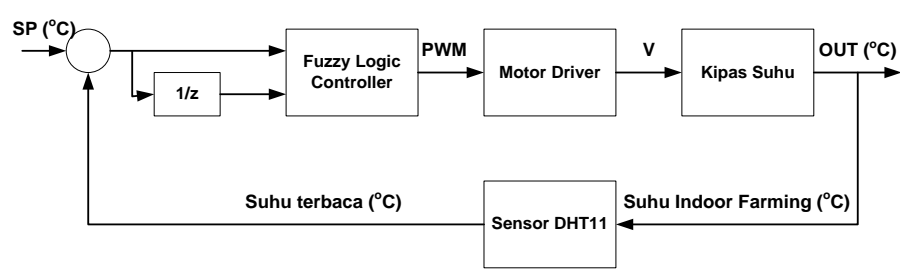

Gambar 7. Diagram blok sistem kontrol fuzzy logic yang digunakan 


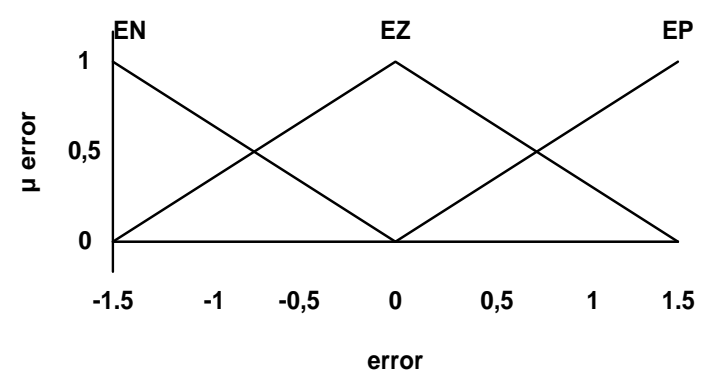

Gambar 8. Fungsi keanggotaan input error

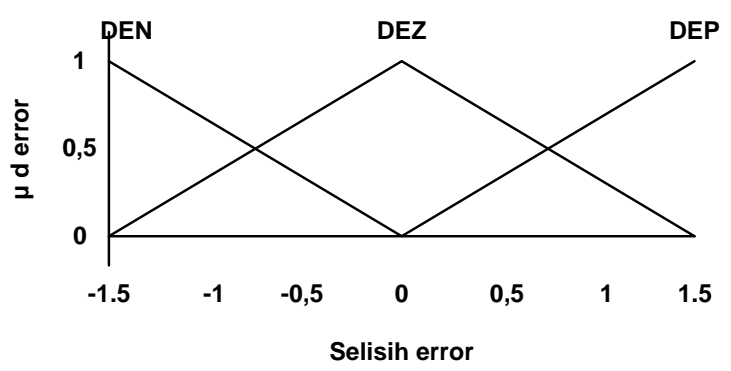

Gambar 9. Fungsi keanggotaan input selisih error

Fungsi keanggotaan yang digunakan adalah fungsi segitiga untuk EZ, dan DEZ. Sedangkan untuk EN, EP, DEN, dan DEP menggunakan fungsi linear. Fungsi segitiga yang digunakan mengacu pada (1) sedangkan fungsi linear mengacu pada (2). Batasan nilai error dan selisih error yang dijadikan input adalah $-1,5$ hingga 1,5 karena rentang nilai tersebut cukup besar jika dibanding dengan kemampuan aktuator. Sehingga jika error dan selisih error diluar -1,5 hingga 1,5 maka aktuator (kipas) akan berputar penuh. Notasi yang dijelaskan pada (1) mengacu pada Gambar 10 sedangkan pada (2) mengacu pada Gambar 11.

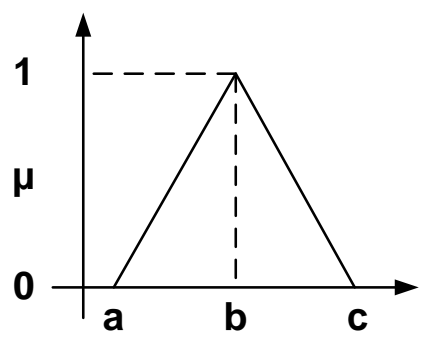

Gambar 10. Fungsi keanggotaan segitiga [10]

$$
\mu[x]_{\text {segitiga }}=\left\{\begin{array}{c}
0 ; \text { jika } x \leq a \text { atau } x \geq c \\
\frac{x-a}{b-a} ; \text { jika } a \leq x \leq b \\
\frac{x-b}{c-b} ; j i k a b \leq x \leq c
\end{array}\right.
$$

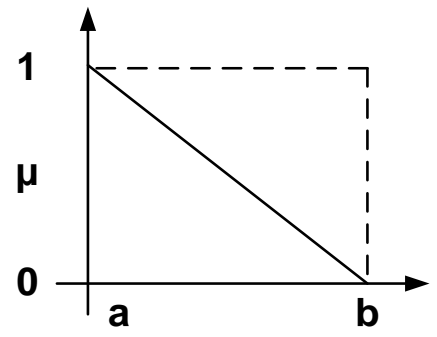

Gambar 11. Fungsi keanggotaan linear [10]

$$
\mu[x]_{\text {linear }}=\left\{\begin{array}{c}
1 ; \text { jika } x \leq a \\
\frac{b-x}{b-a} ; \text { jika } a<x<b \\
0 ; \text { jika } x \geq b
\end{array}\right.
$$

Berdasarkan (1) dan (2) maka setiap fungsi keanggotaan input error dan input selisih error akan menghasilkan himpunan keanggotaan sebagai yang tertera pada (3) dan (4).

$$
\begin{aligned}
& \mu_{\text {error }}[x]=\left[\mu_{E N}, \mu_{E Z}, \mu_{E P}\right] \\
& \mu_{\text {derror }}[x]=\left[\mu_{D E N}, \mu_{D E Z}, \mu_{D E P}\right]
\end{aligned}
$$

Mikrokontroler yang digunakan mendukung pembangkitan sinyal PWM dengan resolusi 8-bit sehingga nilai duty cycle $0 \%-100 \%$ dapat diwakili oleh nilai desimal 0-255. Nilai 0-255 merupakan nilai register OCRx yang ada di mikrokontroler. Fungsi keanggotaan output menggunakan singleton membership function yang nilainya ditunjukkan pada Gambar 12. Terdapat lima himpunan keanggotaan output antara lain sangat lambat (SL), lambat (L), sedang (S), cepat (C) dan sangat cepat (SC).

Salah satu komponen logika fuzzy yang terpenting adalah aturan-aturan atau rule evaluation. Dalam aturan ini terdapat hubungan if-then antara nilai output pada setiap kombinasi input. Tabel 1 menunjukan nilai output pada setiap kombinasi input error dan selisih error. Fungsi implikasi yang digunakan adalah AND sehingga kombinasi dari kedua input dapat ditulis seperti (5).

$\mu_{\text {error } \cap \text { derror }}[x]=\min \left(\mu_{\text {error }}[x], \mu_{\text {derror }}[x]\right)$

Proses terakhir adalah proses defuzifikasi untuk mendapatkan nilai PWM berdasarkan output yang telah didapatkan. Defuzifikasi yang dilakukan menggunakan metode centre of gravity yang dapat dilihat pada (6). 


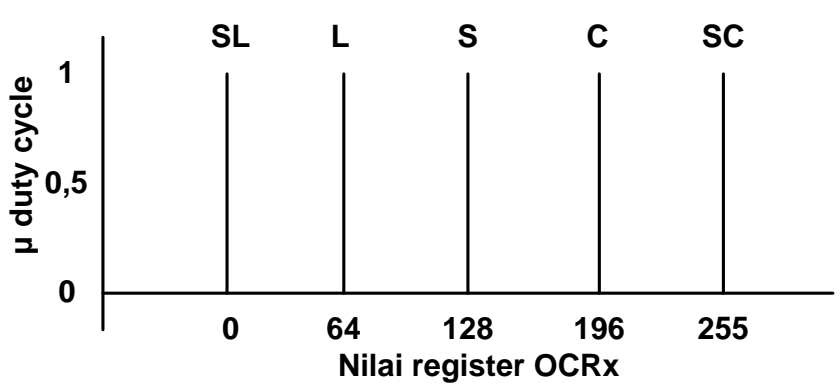

Gambar 12. Fungsi keanggotaan output $\mathrm{DC}_{\mathrm{PWM}}$

Tabel 1. Evaluasi rule Fuzzy Logic yang digunakan

\begin{tabular}{cccc}
\hline & EN & EZ & EP \\
\hline DEN & SC & C & S \\
\hline DEZ & C & S & L \\
\hline DEP & S & L & SL \\
\hline
\end{tabular}

$$
D C_{P W M}=\frac{\sum_{i=1}^{n} x_{i} \cdot \mu\left(x_{i}\right)}{\sum_{i=1}^{n} \mu\left(x_{i}\right)}
$$

Dimana i adalah jumlah kombinasi input membership function dalam rule. $x_{i}$ adalah output memership function saat i. $\mu\left(x_{i}\right)$ merupakan nilai fungsi keanggotaan setelah dimasukan ke fungsi implikasi. Sebagai contoh perhitungan, jika nilai error bernilai 1 dan selisih error sebesar 0,5 maka berdasarkan (1) dan (2) akan di dapatkan nilai derajat keanggotaan sebagai berikut

$$
\begin{aligned}
& \mu_{\text {error }}[1]=[0,0.33,0,67] \\
& \mu_{\text {derror }}[0.5]=[0,0.67,0,33]
\end{aligned}
$$

Selanjutnya dengan mengacu pada Tabel 1, jika EZ AND DEZ maka akan menghasilkan S, EZ AND DEP menghasilkan L, EP AND DEZ menghasilkan L, dan EP AND DEP menghasilkan SL. Hasil kombinasi input setelah dimasukan fungsi implikasi adalah sebagai berikut.

$$
\begin{aligned}
& \mu_{E Z \cap d D E Z}[x]=\min (0.33,0.67)=0.33 \\
& \mu_{E Z \cap d D E P}[x]=\min (0.33,0.33)=0.33 \\
& \mu_{E P \cap d D E Z}[x]=\min (0.67,0.67)=0.67 \\
& \mu_{E P \cap d D E P}[x]=\min (0.67,0.33)=0.33
\end{aligned}
$$

Dengan menggunakan (6) maka didapatkan nilai $\mathrm{DC}_{\mathrm{PWM}}$ sebagai berikut.

$$
\begin{aligned}
D C_{P W M} & =\frac{0.33 S+0.33 L+0.67 L+0.33 S L}{0.33+0.33+0.67+0.33} \\
& =\frac{0.33(128)+0.33(64)+0.67(64)+0.33(0)}{1.67} \\
& =\frac{106.24)}{1.67}=63,61
\end{aligned}
$$

Nilai register OCRx dalam mikrokontroler hanya dapat diisi oleh tipe data integer sehingga nilai 63,61 dibulatkan menjadi 64. Sehingga pada kondisi tersebut nilai register OCRx diberi nilai 64 .

\section{Hasil dan Pembahasan}

Untuk mengetahui performa sistem kontrol dalam mengatur suhu di dalam farming box maka dilakukan beberapa pengujian. Pengujian yang dilakukan meliputi kalibrasi sensor dan perhitungan waktu sistem kontrol untuk mencapai set poin.

\section{A. Pengujian dan kalibrasi sensor suhu}

Sebelum sensor digunakan, terlebih dahulu dilakukan proses kalibrasi. Sebagai data pembanding digunakan thermometer digital HTC-1. Alat tersebut merupakan thermometer digital sekaligus hygrometer sehingga dapat pula digunakan untuk mengukur kelembaban udara.

\begin{tabular}{|c|c|c|c|}
\hline No & HTC-1 $\left({ }^{\circ} \mathrm{C}\right)$ & Sensor $\left({ }^{\circ} \mathrm{C}\right)$ & $\begin{array}{c}\text { Error } \\
\text { mutlak } \\
(\%)\end{array}$ \\
\hline 1 & 28 & 27,3 & 2,50 \\
\hline 2 & 28,5 & 27,9 & 2,11 \\
\hline 3 & 29 & 28,7 & 1,03 \\
\hline 4 & 29,5 & 29,4 & 0,34 \\
\hline 5 & 30 & 29,7 & 1,00 \\
\hline 6 & 30,5 & 30,3 & 0,66 \\
\hline 7 & 31 & 30,6 & 1,29 \\
\hline \multicolumn{3}{|c|}{ Rata-rata error mutlak } & 1,27 \\
\hline \multicolumn{3}{|c|}{ Standar Deviasi } & 0,77 \\
\hline
\end{tabular}
Proses kalibrasi diawali dengan membandingkan suhu hasil pembacaan sensor dengan pembacaan thermometer HTC-1. Pembacaan dilakukan dari rentang $28^{\circ} \mathrm{C}$ hingga $33^{\circ} \mathrm{C}$. Pada pengukuran tersebut terjadi selisih pembacaan dengan nilai antara $0,34 \%$ hingga $2,50 \%$. Rata-rata error yang dihasilkan adalah 1,27\% dengan standar deviasi sebesar $0,77 \%$. Hasil selengkapnya dapat dilihat pada Tabel 2.

Tabel 2. Hasil pembacaan sensor sebelum kalibrasi

Pembacaan sensor sebelum kalibrasi cenderung lebih rendah dari pembacaan HTC-1 sehingga hasil pembacaan sensor perlu di naikkan. Proses kalibrasi dilakukan dengan menggunakan regresi linear. Dengan menggunakan (4) maka diharapkan error yang terjadi semakin kecil.

$$
\hat{y}=0,97234 x+1.21474
$$


Tabel 3. Hasil pembacaan sensor setelah kalibrasi

\begin{tabular}{cccc}
\hline No & HTC-1 $\left({ }^{\mathbf{} C}\right)$ & Sensor $\left({ }^{\mathbf{O}} \mathbf{C}\right)$ & $\begin{array}{c}\text { Error } \\
\text { mutlak } \\
(\%)\end{array}$ \\
\hline 1 & 28 & 27,76 & 0,86 \\
\hline 2 & 28,5 & 28,34 & 0,55 \\
\hline 3 & 29 & 29,12 & 0,42 \\
\hline 4 & 29,5 & 29,80 & 1,02 \\
\hline 5 & 30 & 30,09 & 0,31 \\
\hline 6 & 30,5 & 30,68 & 0,58 \\
\hline 7 & 31 & 30,97 & 0,10 \\
\hline \multicolumn{4}{c}{ Rata-rata error mutlak } \\
\hline \multicolumn{4}{c}{ Standar Deviasi } \\
\hline
\end{tabular}

Setelah dilakukan kalibrasi, nilai error berkurang menjadi kisaran $0,1 \%$ hingga $1,02 \%$. Nilai error tertinggi berada pada suhu 29,5 oC yaitu sebesar $1,02 \%$. Sedangkan error terkecil terjsadi saat suhu $31^{\circ} \mathrm{C}$ dimana error yang terjadi hanya $0,10 \%$. Dengan rata-rata error sebesar $0,55 \%$ dan standar deviasi $0,31 \%$ maka hasil setelah kalibrasi menunjukan kenaikan performa dibandingkan hasil sebelum kalibrasi.

\section{B. Pengujian tanpa sistem kontrol}

Pengujian tanpa sistem kontrol dilakukan dengan cara mengaktifkan kipas dengan kecepatan penuh. Respon yang diperoleh nantinya akan dibandingkan dengan respon yang dihasilkan sistem kontrol. Kondisi awal pengujian, suhu yang terukur sebesar $31,6^{\circ} \mathrm{C}$ kemudian kipas dinyalakan dengan kecepatan penuh. Respon yang didapatkan ditunjukan oleh Gambar 13.

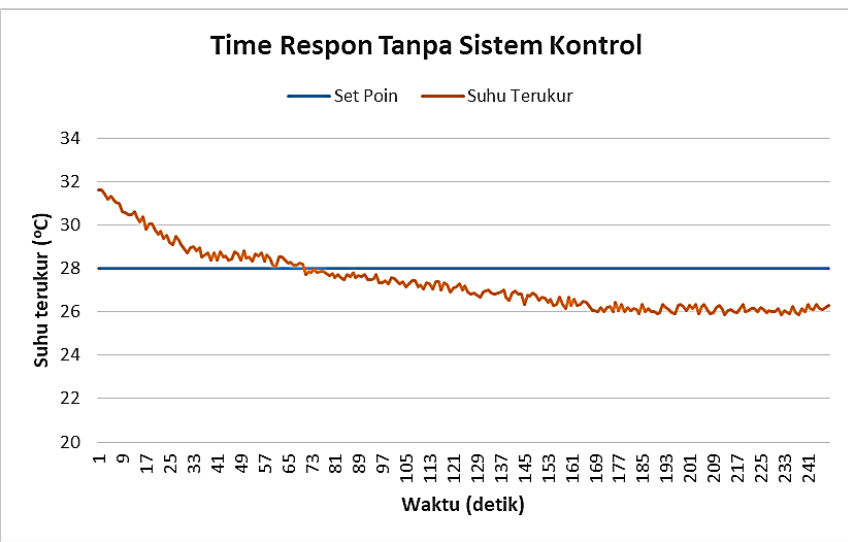

Gambar 13. Time respon tanpa sistem kontrol

Dari respon yang didapatkan, terlihat bahwa suhu turun dari $31,6^{\circ} \mathrm{C}$ menjadi $26^{\circ} \mathrm{C}$ dengan waktu 165 detik. Setelah detik ke 165 suhu stabil di kisaran $26^{\circ} \mathrm{C}$ hingga $26,4^{\circ} \mathrm{C}$. Dengan error mencapai $2^{\circ} \mathrm{C}$ maka steady state error yang didapatkan $7,14 \%$. Berdasarkan hasil tersebut maka sistem kontrol memang diperlukan agar dapat mengatur suhu stabil di set poin $28^{\circ} \mathrm{C}$.

\section{Pengujian performa sistem kontrol}

Pengujian performa sistem kontrol ini bertujuan untuk mengetahui error steady state dan settling time yang dihasilkan oleh sistem kontrol. Pengujian ini dilakukan dengan cara menjalankan sistem kontrol pada suhu ruang. Suhu ruang yang terukur adalah sebesar $31,6^{\circ} \mathrm{C}$. Sistem kontrol akan bekerja mendinginkan farming box hingga mencapai set poin. Set poin yang telah ditentutkan sebesar $28^{\circ} \mathrm{C}$. Respon waktu dari sistem kontrol dapat dilhat pada grafik Gambar 14.

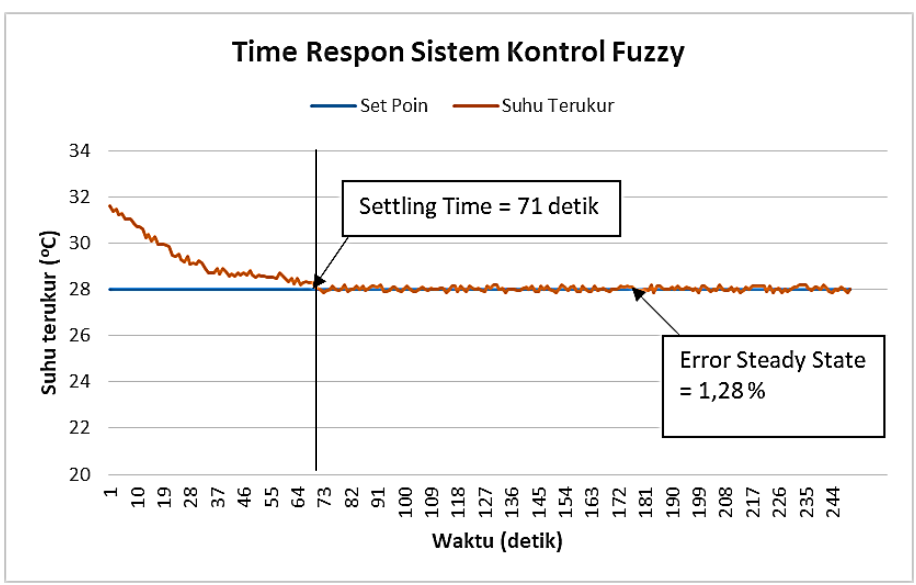

Gambar 14. Time respon sistem kontrol tanpa gangguan

Dari Gambar 14 dapat dilihat bahwa sistem kontrol berhasil menurunkan suhu dari $31,6^{\circ} \mathrm{C}$ menjadi $28^{\circ} \mathrm{C}$ dalam waktu 71 detik. Setelah detik ke 71 , nilai suhu terukur konstan antara $27,92^{\circ} \mathrm{C}$ hingga $28,27^{\circ} \mathrm{C}$ yang berarti memiliki error sebesar $1,28 \%$ terhadap set poin.

\section{Pengujian performa sistem kontrol dengan gangguan}

Pengujian terhadap performa sistem kontrol dilanjutkan dengan menguji kemampuan kontroler saat diberi gangguan. Gangguan yang diberikan adalah dengan memberikan udara dari luar box yang cenderung lebih panas. Hal ini akan menyebabkan udara di dalam box kembali naik. Respon waktu sistem kontrol saat terkena gangguan ditunjukkan pada Gambar 15.

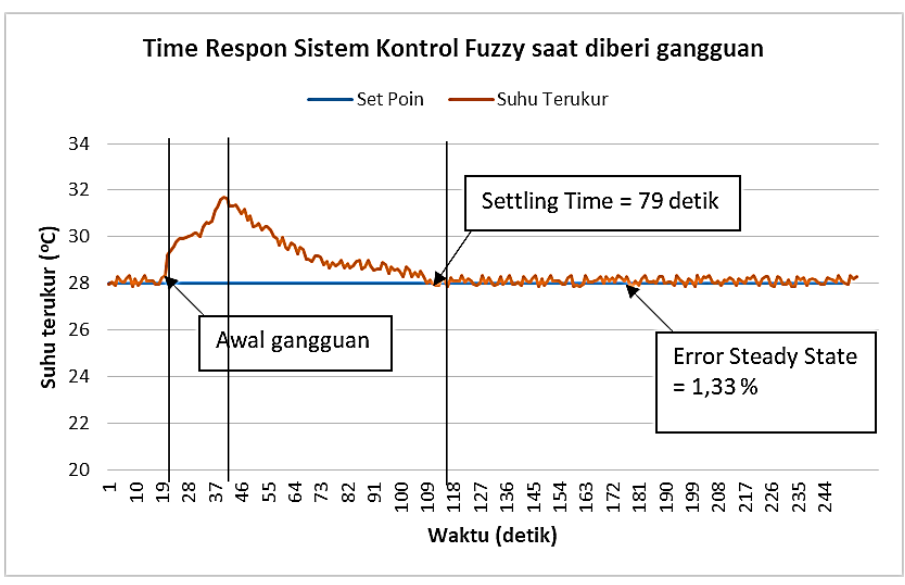

Gambar 15. Time respon sistem kontrol dengan gangguan 
Pada 20 detik pertama pengukuran, kondisi suhu di dalam box stabil di $28^{\circ} \mathrm{C}$. Setelah itu udara dari luar dimasukan hingga mencapai suhu $31,8^{\circ} \mathrm{C}$ di detik ke 41 . Sistem kontrol selanjutnya menurunkan suhu hingga kembali stabil di kisaran suhu $27,91^{\circ} \mathrm{C}$ hingga $28,28^{\circ} \mathrm{C}$ pada detik ke 110. Dari pengujian yang telah dilakukan, menunjukan bahwa performa fuzzy logic controller cukup bagus dalam mengatur suhu ruangan dalam farming box. Performa tersebut jika dibandingkan dengan tanpa kontrol yang memiliki steady state error lebih dari $7 \%$.

\section{Kesimpulan}

Rancang bangun farming box dalam penelitian ini mampu bekerja sesuai dengan yang diinginkan sebab menunjukan hasil yang lebih baik dari pada penerapan tanpa kontrol. Suhu di dalam box berhasil diturunkan dan dijaga pada nilai konstan. Berdasarkan hasil pengujian yang telah dilakukan, sistem kontrol logika fuzzy (fuzzy logic controller) mampu mengatur suhu menuju set poin dalam waktu 71 detik tanpa gangguan dan 69 detik saat ada gangguan. Steady state error yang didapatkan cukup kecil yaitu 1,28\% tanpa gangguan dan 1,33\% dengan gangguan. Hasil tersebut cukup bagus jika dibandingkan dengan pengujian tanpa sistem kontrol yang memiliki error hingga $7,14 \%$. Berdasarkan data tersebut maka bisa disimpulkan sistem kontrol sudah bekerja dengan baik. Perbaikan kedepan yang bisa dilakukan adalah memperbaiki sistem kontrol agar bisa mendapatkan error steady state yang lebih kecil dan settling time yang lebih cepat. Misalnya dengan menambahkan himpunan keanggotaaan atau mengubah fungsi keanggotaan fuzzy logic controller Selain itu kontrol kelembaban bisa diterapkan pada farming box ini.

\section{UCAPAN TERIMA KASIH}

Dalam kesempatan ini, penulis mengucapkan terima kasih kepada rekan di Jurusan Teknik Elektro ITATS karena dengan dukunganya, penelitian ini dapat selesai dan dipublikasikan ke masyarakat.

\section{Daftar Pustaka}

[1] Urban Agriculture as a Solution to Food Insecurity: West Oakland and People's Grocery. 2000.

[2] S. M. Sibarani, "Analisis sistem irigasi hidroponik NFT (nutrient film technique) pada tanaman budidaya tanaman selada (Lactuca sativa var crispa L.)," Dec. 2012, Accessed: Jul. 02, 2020. [Online]. Available: http://repository.usu.ac.id/handle/123456789/34838.

[3] K. Wijaya, J. Jubaidah, and A. J. D. Astuti, "URBAN FARMING BERBASIS AQUAPONIC SYSTEM," $J$. Pembang. Perkota., vol. 5, no. 2, Art. no. 2, Dec. 2017.

[4] M. A. R. Hakim, S. Sumarsono, and S. Sutarno, "Pertumbuhan dan produksi dua varietas selada (Lactuca sativa 1.) pada berbagai tingkat naungan dengan metode hidroponik," J. Agro Complex, vol. 3, no. 1, Art. no. 1, Jun. 2019, doi: 10.14710/joac.3.1.15-23.

[5] N. Nilawati, D. W. Ganefianti, and D. Suryati, "Variabilitas Genetik dan Heritabilitas Pertumbuhan dan
Hasil 26 Genotipe Tomat," Akta Agrosia, vol. 20, no. 1, Art. no. 1, 2017, doi: 10.31186/aa.20.1.25-34.

[6] M. S. Fikri, D. Indradewa, and E. T. S. Putra, "PENGARUH PEMBERIAN KOMPOS LIMBAH MEDIA TANAM JAMUR PADA PERTUMBUHAN DAN HASIL KANGKUNG DARAT (Ipomoea reptans Poir.),"Vegetalika, vol. 4, no. 2, Art. no. 2, Apr. 2016, doi: 10.22146/veg.9277.

[7] "What is a Farm in a Box? | AgriTechTomorrow." //agritechtomorrow.com/article/2017/11/what-is-a-farmin-a-box/10339/ (accessed Jul. 03, 2020).

[8] R. R. Pambayun and S. Sumarna, "OTOMATISASI PENGENDALIAN SUHU PADA GREENHOUSE," E- $J$. Fis., vol. 5, no. 7, Art. no. 7, Nov. 2016.

[9] M. A. Nahdi, T. Y. Putro, and Y. Sudarsa, "Sistem Pemantauan dan Kendali Suhu Nutrisi Tanaman Hidroponik Berbasis IOT," Pros. Ind. Res. Workshop Natl. Semin., vol. 10, no. 1, Art. no. 1, Aug. 2019, doi: 10.35313/irwns.v10i1.1390.

[10] M. Y. E. Adiptya and H. Wibawanto, "Sistem Pengamatan Suhu dan Kelembaban Pada Rumah Berbasis Mikrokontroller ATmega8," J. Tek. Elektro, vol. 5, no. 1, Art. no. 1, 2013, doi: 10.15294/jte.v5i1.3548.

[11] E. Gauss, "Operator Himpunan Fuzzy - ppt download." https://slideplayer.info/slide/14874365/ (accessed Jul. 02, 2020). 